\title{
Mathematical modeling of moisture evaporation in co-current foam spray drying
}

\section{Jaskulski, M. ${ }^{{ }^{*}}$; Lewandowski, A. ${ }^{\text {a }}$ Zbiciński, I. ${ }^{\mathrm{a}}$}

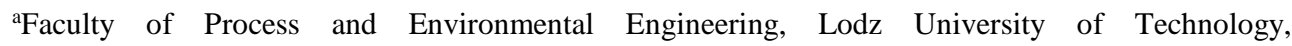
Wolczanska Str 213., 95-924 Lodz, Poland.

*E-mail of the corresponding author: maciej.jaskulski@p.lodz.pl

\begin{abstract}
Two models of foam drying are presented in the paper: single droplet drying and perfect mixing of phases spray drying models to describe mechanism of drying of droplet containing bubble.

Analysis of drying curves shows that in constant drying rate period and in the falling drying rate period, evaporation rate decreases due to particle shrinkage and increasing of resistance of moisture diffusion inside the solid crust. Increase of gas pressure in the bubble might cause particle breakage.

Slight differences between theoretical and experimental results caused by disregarding broken particles in the simulations proves accuracy of the developed model.
\end{abstract}

Keywords: spray drying, modeling, foamed materials, particle morphology 


\section{Introduction}

Foaming of slurry in spray drying processes is a method to control rheological properties of feed like viscosity and density and morphology of powder. Powders obtained in foam spray drying process are characterized by lower bulk density, high porosity and particle sizes, enhanced solubility and wettability in relation to conventional spray drying. However, to control product quality, foam spray drying process must to be carried out in specific window of the process parameters selected individually for dried material.

In the literature there is lack of mathematical description of foamed spray drying process; existing models refer only to the constant drying rate period [1].

The aim of this work was to develop and validate mathematical model of foam spray drying process to determine morphological changes of particles and to estimate the quality of the product.

\section{Foam spray drying model}

Two models of foam drying were developed in the frame of the work: single droplet drying (SDD) model to check correctness of applied correlations and perfect phase mixing foam spray drying model to simulate drying process. All calculations were performed in Matlab and validated on a base of data obtained from the foam spray drying experiments performed at Lodz University of Technology [2].

\subsection{Single droplet drying model}

SDD model describes moisture evaporation of maltodextrin solution (DE12) from stationary droplet which contains a single saturated nitrogen bubble in constant ambient air temperature $T_{G}$, and humidity $Y_{G}$. In constant drying rate period, droplet shrinks due to water evaporation whereas in falling drying rate period, particle shrinkage stops because of crust solidification. In this period pressure in the gas bubble increases and might cause particle brakeage. The model allows to determine drying curves, particle density, porosity, crust thickness and pressure in the internal bubble.

\subsubsection{Heat transfer}

Moisture from the particle evaporates to surrounding air in temperature which, taking into account heat capacity of air and internal bubble, can be calculated from equation (1):

$\frac{d T_{p}}{d t}=\frac{A_{p} \alpha_{p}\left(T_{p}-T_{G}\right)+h\left(\frac{d m_{p, a}}{d t}+\frac{d m_{p, b}}{d t}\right)}{m_{p} c_{p}+m_{b} c_{b}}$ 


\subsubsection{Mass transfer}

Mass transfer model was based on the concept of characteristic drying curves [3]. Overall evaporation from the droplet/particle is a sum of moisture evaporation to the surrounding air and to the internal bubble, eq. (2):

$\frac{d m_{p}}{d t}=\frac{d m_{p, a}}{d t}+\frac{d m_{p, b}}{d t}$

Evaporation rate to drying air is calculated from the equation:

$\frac{d m_{p, a}}{d t}=f M_{w} A_{p} \beta_{p}\left(C_{s}-C_{G}\right)$

where heat and mass transfer coefficients $\left(\alpha_{p}\right.$ and $\left.\beta_{p}\right)$ were calculated from McAdams correlations. Amount of water transferred to the bubble was determined from eq. (4):

$\frac{d m_{p, \mathrm{~b}}}{d t}=m_{N} \frac{M_{w}}{M_{N}}\left(\frac{P_{s t}}{P_{a}-P_{s t}}\right) \frac{1}{d t}$

To take into account decrease of drying rate (eq. (3)) in the falling drying rate period, coefficient $f$ defined by relation (5) was used [5]. In constant drying rate period coefficient $f$ is equal $f=1$. After critical moisture content, due to increase in internal mass transfer resistance, $f$ decreases to $f=0$ at the equilibrium point. According to Woo et al. [4] coefficient $f$ can be expressed as a function of moisture content:

$f=\left(\frac{X-X_{e q}}{X_{c r}-X_{e q}}\right)^{3.22}$

Critical moisture content for maltodextrin was determined experimentally in a frame of this work and calculated from eq.(5), $\left(T_{G}\right.$ in $\left.{ }^{\circ} \mathrm{C}\right)$ :

$X_{c r}=21555 \cdot T_{G}^{-2.106} \quad \mathrm{R}^{2}=0.976$

Equilibrium moisture content was calculated from GAB equation [5]:

$X_{e q}=\frac{X_{m o} c k a_{w}}{\left(1-k a_{w}\right)\left[1+(c-1) k a_{w}\right]}$

Where constants $c=10.866$ and $k=0.971$. Monolayer moisture content $\left(X_{m o}\right)$ for maltodextrin is equal to $0.0518 \mathrm{~kg} / \mathrm{kg}$.

\subsubsection{Particle morphology}

Particle diameter was calculated from the sum of the volumes of liquid and internal gas bubble: 
$d_{p}=\sqrt[3]{\frac{6\left(V_{L}+V_{b}\right)}{\pi}}$

In the constant drying rate period, change of liquid shell volume resulting from evaporation of moisture can be calculated from equation (9):

$V_{L}=\frac{\rho_{L, 0}\left(1+X_{c r}\right)}{\rho_{L}\left(1+X_{0}\right)} \frac{\pi}{6} d_{p, 0}^{3}$

In the falling drying rate period, particle can shrink due to thermal deformations of solidified crust. Particle shrinkage can be determined using modified equation proposed by Chen [6]:

$V_{L}=\frac{\pi}{6}\left[d_{p, c r}\left(b+(1-b) \frac{X}{X_{c r}}\right)\right]^{3}$

Shrinkage coefficient $b$ was calculated as a ratio of particle diameter when particle moisture content is equal to critical moisture content, to the final particle diameter measured experimentally. Equation (11) describes $b$ as a function of drying air temperature $\left(T_{G}\right.$ in $\left.{ }^{\circ} \mathrm{C}\right)$ :

$b=0.41+0.0038 T_{G}-6.97 \cdot 10^{-6} T_{G}^{2} \quad \mathrm{R}^{2}=0.971$

Volume of the internal bubble was calculated from the current bubble mass and density (12):

$V_{b}=\frac{m_{b}}{\rho_{b}}$

Density of the bubble depends also on the gas humidity and can be determined from equation (13):

$\rho_{b}=\frac{P_{b}}{\frac{R}{M_{N}} T_{p}}\left(1+Y_{b}^{*}\right) \frac{1}{1+Y_{b}^{*} \frac{M_{N}}{M_{w}}}$

Equation (12) can be transformed to equation (14) to calculate bubble diameter:

$d_{b}=\sqrt[3]{\frac{6 V_{b}}{\pi}}$

Having diameter of particles $\left(d_{p}\right)$ and bubbles $\left(d_{b}\right)$, crust thickness (particle wall thickness) can be determined.

In constant drying rate period, pressure inside the particle was equal to the ambient pressure $P_{b}=P_{a}$. To calculate gas pressure inside the bubble in the falling drying rate period, we assumed proportional grow of pressure with particle temperature in isochoric process according to the equation (15): 
$P_{b}=P_{a} \frac{T_{p}}{T_{p, c r}}$

Selected results of calculations are presented in Fig. 1. Fig. 1 shows grow of solid concentration and drying curve for the same initial bubble diameter and different initial droplet diameters.

Fig. 1 Solid concentration and evaporation rate from SDD model.

We may observe that as bigger droplet contains more liquid to be evaporated (initial bubble diameter is the same), particle solid concentration grows slower. Analysis of drying curves shows that in constant drying rate period evaporation rate slightly decreases due to particle shrinkage; in the falling drying rate period $\left(X<X_{c r}=0.5 \mathrm{~kg} / \mathrm{kg}\right)$, drying rate falls down due to increasing of internal resistance of moisture diffusion inside the solid crust. Shape of drying curves is characteristic for evaporation from single droplets which confirms correctness of physical model of the process.

\subsection{Co-current foam spray drying model}

In co-current foam spray drying model air temperatures, particle velocities and air humidity were calculated from the heat, mass and momentum balance, equations (17) - (22) [7]. Foam spray drying calculations were carried out for perfect mixing of phases, axisymetrical flow of air and particles and monodispersed atomization. Momentum transfer between drying air and particles was determined from classical equations:

$\frac{d v_{p, x}}{d t}=g\left(1-\frac{\rho_{G}}{\rho_{p}}\right)-\frac{3}{4} C_{D} \frac{v_{p}\left(v_{p, x}-v_{G, x}\right) \rho_{G}}{\rho_{G} d_{p}}$ 


$$
\begin{aligned}
& \frac{d v_{p, r}}{d t}=-\frac{3}{4} C_{D} \frac{v_{p}\left(v_{p, r}-v_{G, r}\right) \rho_{G}}{\rho_{G} d_{p}} \\
& \frac{d v_{p, z}}{d t}=-\frac{3}{4} C_{D} \frac{v_{p}\left(v_{p, z}-v_{G, z}\right) \rho_{G}}{\rho_{G} d_{p}}
\end{aligned}
$$

where $v_{p}$ is relative particle velocity. Air humidity was calculated from mass balance:

$\frac{d Y_{G}}{d t}=\frac{-\dot{M}_{L}}{\dot{M}_{G} \rho_{G}}\left(\frac{\frac{d m_{p}}{d t}(1+X)}{m_{p, 0} C_{0}+m_{p, w}}\right)$

Particle moisture content was determined from equation (21):

$\frac{d X}{d t}=\frac{\frac{d m_{p}}{d t}+\left(Y_{e q} \cdot m_{N}-m_{G, W}\right)(1+X)}{m_{p, 0} C_{0}+m_{p, w}}$

Air temperature was determined from heat balance (22):

$\frac{d T_{G}}{d t}=\frac{1}{\dot{M}_{G} c_{G}}\left(-\dot{M}_{G}\left(c_{v} T_{G}+h\right) \frac{d Y_{G}}{d t}-\dot{M}_{L}\left(X c_{w}+c_{S}\right) \frac{d T_{p}}{d t}-\dot{M}_{L} c_{w} T_{p} \frac{d X}{d t}\right)$

Selected results of calculations are shown in Fig.2. Figure 2 presents comparison of theoretically and experimentally determined wall thickness and particle density for different air temperatures and foaming gas rate. Final density of the material determined from the mathematical model decreased from $1300 \mathrm{~kg} / \mathrm{m}^{3}$ to $600 \mathrm{~kg} / \mathrm{m}^{3}$, which is in line with the experimental results. Differences in relation to the experiments are caused by disregarding broken particles in the simulations. Decrease in the wall thickness depends on the amount of gas introduced into the interior of the droplet. The higher degree of foaming, the larger gas bubble is trapped in the particle and the less material forms the particle.

Fig. 2 Wall thickness and particle apparent density for a different air temperatures and different foaming gas rate. 


\section{Conclusions}

Model of co-current foamed spray drying was developed to determine mechanism of droplet drying containing a single bubble.

Analysis of theoretical and experimental results shows that particle solid concentration grows slower for bigger droplet as it contains more liquid to be evaporated as initial bubble diameter is the same. In constant drying rate period evaporation rate slightly decreases due to particle shrinkage which typical for evaporation from droplets and confirms correctness of physical model of the process.

Density of the material determined from the mathematical model decreased twofold in relation to the initial which was in line with the experimental results. Decrease in the wall thickness is a function of the amount of gas introduced into the interior of the droplet. Particle wall thickness and particle density for different air temperatures and foaming gas rate are in line with the experimental results. Differences in relation to the experiments are caused by disregarding broken particles in the simulations.

\section{Nomenclature}

\begin{tabular}{|c|c|c|c|c|c|}
\hline A & surface & $\mathrm{m}^{3}$ & $\mathrm{~T}$ & temperature & ${ }^{\circ} \mathrm{C}$ \\
\hline c & specific heat & $\mathrm{J} \mathrm{kg}^{-1} \mathrm{~K}^{-1}$ & $\mathrm{t}$ & time & $\mathrm{s}$ \\
\hline C & $\begin{array}{l}\text { vapor } \\
\text { concentration }\end{array}$ & $\mathrm{kg} \mathrm{mol} \mathrm{m}^{-3}$ & $\mathrm{v}$ & velocity & $\mathrm{m} \mathrm{s}^{-1}$ \\
\hline h & $\begin{array}{l}\text { heat of } \\
\text { evaporation }\end{array}$ & $\mathrm{J} \mathrm{kg}^{-1}$ & V & volume & $\mathrm{m}^{3}$ \\
\hline $\mathrm{m}$ & mass & $\mathrm{kg}$ & $\mathrm{X}$ & moisture content & $\mathrm{kg} \mathrm{kg}^{-1}$ \\
\hline M & molar weight & $\mathrm{kg} \mathrm{mol}^{-1}$ & $\mathrm{Y}^{*}$ & $\begin{array}{l}\text { saturated } \\
\text { humidity }\end{array}$ & $\mathrm{kg} \mathrm{kg}^{-1}$ \\
\hline$P$ & pressure & $\mathrm{Pa}$ & $\mathrm{R}$ & $\begin{array}{l}\text { universal } \\
\text { constant }\end{array}$ & $\mathrm{J} \mathrm{mol}^{-1} \mathrm{~K}^{-1}$ \\
\hline
\end{tabular}

Greek letters

$\begin{array}{lll}\square & \text { heat transfer coefficient } & \mathrm{Wm}^{-2} \mathrm{~K}^{-1} \\ \beta & \text { mass transfer coefficient } & \mathrm{ms}^{-1} \\ \sigma & \text { stress } & \mathrm{Pa}\end{array}$

Subscripts

\begin{tabular}{ll|ll}
0 & initial & L & liquid \\
$\mathrm{a}$ & ambient & $\mathrm{N}$ & nitrogen \\
$\mathrm{b}$ & bubble & $\mathrm{P}$ & particle
\end{tabular}




$\begin{array}{ll}\text { cr } & \text { critical } \\ \text { eq } & \text { equilibrium } \\ \text { G } & \text { gas }\end{array}$

\begin{tabular}{|ll} 
s & surface \\
st & saturation \\
w & water
\end{tabular}

\section{References}

[1] D. D. Frey and C. J. King, "Experimental and theoretical investigation of foam-spray drying. 1. Mathematical model for the drying of foams in the constant-rate period," Ind. Eng. Chem. Fundam., vol. 25, no. 4, pp. 723-730, Nov. 1986.

[2] I. Zbicinski and J. Rabaeva, “Analysis of Gas Admixing Foam Spray-Drying Process,” Dry. Technol., vol. 28, no. 1, pp. 103-110, Dec. 2009.

[3] R. B. Keey and M. Suzuki, “On the Characteristic Drying Curve,” Int. J. Heat Mass Transf., vol. 17, no. 12, pp. 1455-1464, 1974.

[4] M. W. Woo, W. R. W. Daud, A. S. Mujumdar, Z. Wu, M. Z. Meor Talib, and S. M. Tasirin, "CFD Evaluation of Droplet Drying Models in a Spray Dryer Fitted with a Rotary Atomizer,” Dry. Technol., vol. 26, no. 10, pp. 1180-1198, Sep. 2008.

[5] M. Jaskulski, P. Wawrzyniak, and I. Zbiciński, "CFD model of particle agglomeration in spray drying,” Dry. Technol., vol. 33, no. 15-16, 2015.

[6] X. Yang, J. Xiao, M.-W. Woo, and X. D. Chen, "Three-Dimensional Numerical Investigation of a Mono-Disperse Droplet Spray Dryer: Validation Aspects and Multi-Physics Exploration,” Dry. Technol., vol. 33, no. 6, pp. 742-756, Apr. 2015.

[7] T. A. G. Langrish, "Multi-scale mathematical modelling of spray dryers," J. Food Eng., vol. 93, no. 2, pp. 218-228, Jul. 2009. 